\title{
Organ donation after death in Ontario: a population-based cohort study
}

\author{
Donald A. Redelmeier MD, Frank Markel PhD, Damon C. Scales PhD
}

\begin{abstract}
- ABSTRACT
Background: Shortfalls in deceased organ donation lead to shortages of solid organs available for transplantation. We assessed rates of deceased organ donation and compared hospitals that had clinical services for transplant recipients (transplant hospitals) to those that did not (general hospitals).
\end{abstract}

Methods: We conducted a population-based cohort analysis involving patients who died from traumatic brain injury, subarachnoid hemorrhage, intracerebral hemorrhage or other catastrophic neurologic conditions in Ontario, Canada, between Apr. 1, 1994, and Mar. 31, 2011. We distinguished between acute care hospitals with and without transplant services. The primary outcome was actual organ donation determined through the physician database for organ procurement procedures.

Results: Overall, 87129 patients died from catastrophic neurologic conditions during the study period, of whom 1930 became actual donors. Our primary analysis excluded patients from small hospitals, reducing the total to 79746 patients, of whom 1898 became actual donors. Patients who died in transplant hospitals had a distribution of demographic characteristics similar to that of patients who died in other large general hospitals. Transplant hospitals had an actual donor rate per 100 deaths that was about 4 times the donor rate at large general hospitals $(5.0$ v. $1.4, p<0.001)$. The relative reduction in donations at general hospitals was accentuated among older patients, persisted among patients who were the most eligible candidates and amounted to about 121 fewer actual donors per year (adjusted odds ratio $0.58,95 \%$ confidence interval $0.36-0.92$ ). Hospital volumes were only weakly correlated with actual organ donation rates.

Interpretation: Optimizing organ donation requires greater attention to large general hospitals. These hospitals account for most of the potential donors and missed opportunities for deceased organ donation.
$\mathrm{M}$ any eligible patients never receive an organ transplant because of biological or psychological human factors that contribute to shortfalls in organ availability. ${ }^{1,2}$ Immune suppression and surgical complications, for example, require that transplant recipients receive centralized care at hospitals staffed by highly specialized clinicians. ${ }^{3.4}$ However, the subtleties of patient preferences, community support and maximizing available organs require that donors be identified from a wide range of general hospitals. ${ }^{2}$ Ultimately, these practices can mean that hospitals responsible for identifying potential donors do not always encounter the patients who received the successful transplantations.

A request for organ donation after death requires initiative, appropriate referral, consent, formal declaration of brain death and maintenance of donor viability at a time when other patients may also require attention. ${ }^{5,6}$ The time pressure is substantial, because incidents often arise on weekends or at night when clinicians are short staffed, sleep deprived and uncertain about diagnosing brain death. ${ }^{7.8}$ The diversity of cultural preferences and distraught emotions in relatives of potential donors can also cause wellintentioned requests to be misunderstood and followed by negative conflict. ${ }^{9,10}$ Hence, the ongoing rates of deceased organ donation represent substantial efforts both in the community and in hospitals. ${ }^{11}$

Decision science research suggests that clinical behaviour does not always follow the standard model of rational thought. ${ }^{12}$ Self-identity, for example, can sometimes influence decisions by shaping people's preferences and defining institutional norms. ${ }^{13-15}$ We questioned whether the difference between hospitals that observe gratifying recipient outcomes and hospitals that initiate
Competing interests: Donald Redelmeier, Frank Markel and Damon Scales have received grant funding from the Trillium Gift of Life Network. Frank Markel has served as president of the Trillium Gift of Life Network. No other competing interests were declared.

This article has been peer reviewed.

Correspondence to: Donald A. Redelmeier, dar@ices.on.ca

CMAJ 2013. DOI:10.1503 /cmaj.122047 
deceased organ donation might potentially contribute to lower donation rates owing to the lost transmission of information and the attitudes of hospitals that do not have transplant programs. To test this question, we assessed deceased organ donation rates and compared hospitals that have clinical services for transplant recipients to hospitals that do not have such services.

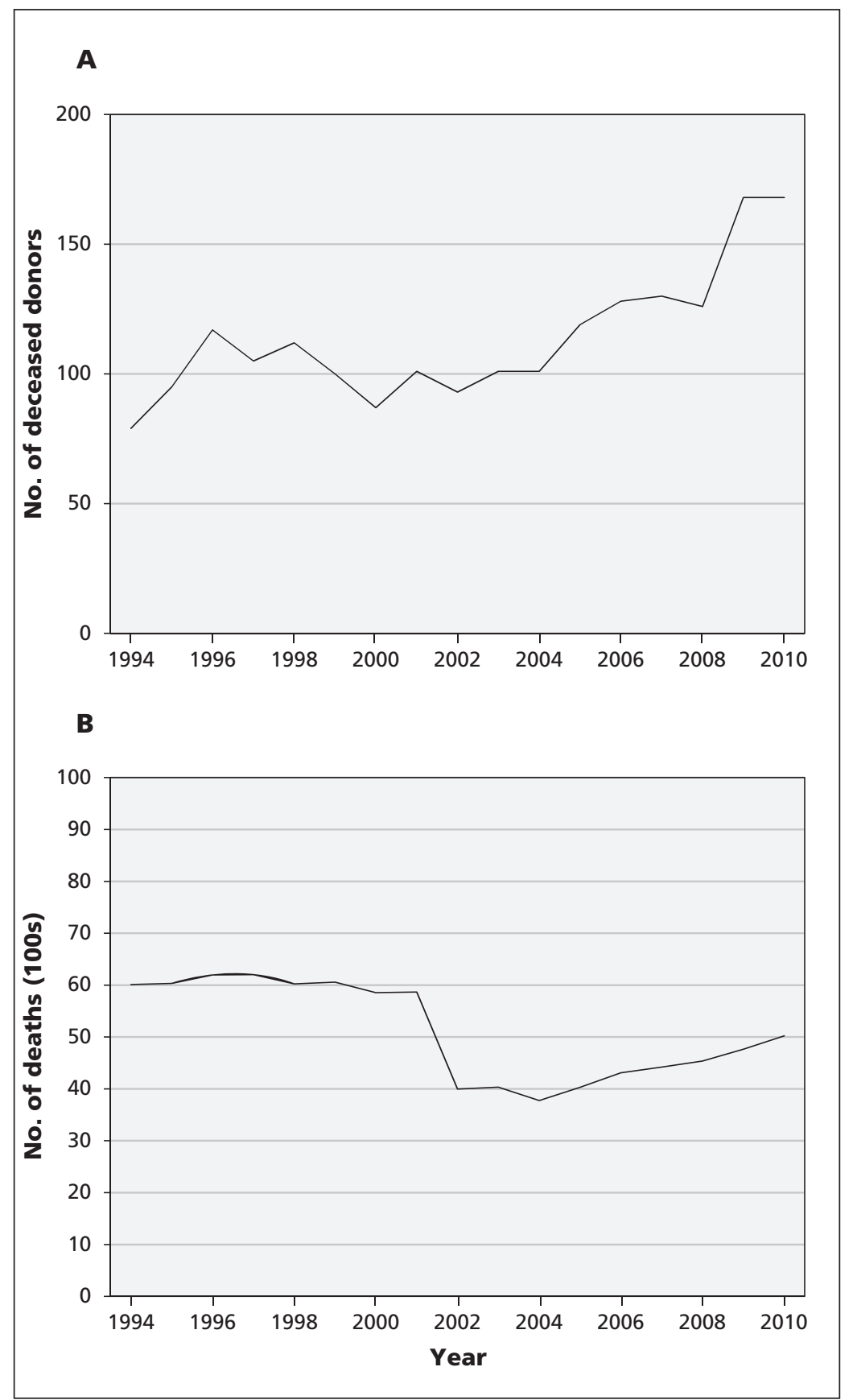

Figure 1: (A) Number of deceased donors and (B) number deaths from catastrophic neurologic conditions during the study period. An anomaly in the numbers of catastrophic neurologic deaths between 2001 and 2002 denotes a change from International Classification of Diseases (ICD), 9th revision, to the ICD 10th revision. An increase in donors over time with a persistent gap between the number of patients who died from catastrophic neurologic conditions and those who became donors can be seen.

\section{Methods}

\section{Patients}

We identified all consecutive patients (children and adults) who died in any Ontario hospital between Apr. 1, 1994, and Mar. 31, 2011, from conditions associated with catastrophic brain injury. We chose this time frame because data were available for all hospitals, the coding system remained mostly unchanged (with the exception of one revision in 2002), and none of the hospitals changed their transplantation designation during this period. We excluded patients who did not have a valid health card identifier. The study was approved by the Sunnybrook Research Ethics Board, including a waiver of individual consent.

\section{Selected causes of death}

The patient's cause of death was classified using the International Classification of Disease (ICD) codes (versions 9 and 10, as appropriate). We included 3 specific conditions that were common causes of brain death, consistently documented in available records and established in previous research. ${ }^{16-18}$ Traumatic brain injury was defined as cerebral laceration, contusion or other intracranial hemorrhage after trauma (ICD codes 800 , 801, 804, 851-853 and S06-S09). Subarachnoid hemorrhage included events related to aneurysms or vascular malformations (ICD codes 430 and I60). Intracerebral hemorrhage included rupture of any cerebral blood vessel or unspecified nontraumatic hemorrhage (ICD codes 431, 432, I61 and I62).

\section{Additional causes of death}

We included 5 additional neurologic causes of death to provide a comprehensive assessment of potential donors: anoxic brain damage (ICD codes 348 and G931), cerebral edema (ICD codes 348 and G936), cerebral infarction (ICD codes 434 and I639), cerebral thrombosis (ICD codes 434, 436, I136, I138, I630-I635, I639 and I640) and asphyxiation (ICD codes 994 and T71).

\section{Patient characteristics}

We obtained patient age at death, sex and residence (urban or rural) through the official vital statistics registry. ${ }^{19}$ We derived patient socioeconomic status using the Statistics Canada algorithm. ${ }^{20}$ We determined previous admissions to hospital and outpatient visits in the year before death using linked databases validated in previous research (i.e., the Canadian Institute for Health Information hospital inpatient database and the Ontario Health Insurance Plan medical outpatient database). ${ }^{21,22}$ We determined comorbid conditions by any physician diagnosis in the 
year before death. ${ }^{23}$ We addressed referral patterns by classifying mode of hospital arrival into 3 groups: direct from the community, by ambulance or transferred from another hospital. The databases did not contain information on patient preferences, religion, race, ethnicity, vital signs, mental status, medications or formal declaration of brain death.

\section{Hospital characteristics}

We focused our attention on where the patient died and distinguished between hospitals that averaged more than 20 deaths per year ("larger hospitals") and those that averaged fewer than 20 deaths per year ("smaller hospitals"). Larger hospitals were further divided into those that had clinical services for transplant recipients ("transplant hospitals") and those that did not ("general hospitals"). Without exception, transplant hospitals announced transplantation services prominently as part of their identity, whereas general hospitals made no mention of such services on public websites or in community services. Otherwise, the hospitals operated under the same regulations, offered similar emergency services and obtained funding through identical fee structures.

\section{Actual organ donation}

We determined solid organ donation through the population-based physician billing database using a comprehensive set of billing codes for any combination of heart, lung, kidney, liver, pancreas or bowel procurement (codes E753, G347, G348, G411, M157, R872, S196, S201, S265, S274, S302 and S436). Some surgeons received funding from alternate payment programs and did not always use such codes; however, anesthesiologists and other clinicians without alternate funding used such codes in all relevant cases. These billing codes are specific $(100 \%, 95 \%$ confidence interval [CI] 99\%-100\%), but not fully sensitive (75\%, 95\% CI 73\%-78\%) when validated through the Trillium Gift of Life Network registry (A.H. Li, Western University, unpublished data).

\section{Subgroup of eligible candidates}

We identified a subgroup of patients who would be the most eligible candidates for organ procurement based on a combination of demographic and clinical data. We used the data from this subgroup to check the robustness of our primary analysis after confining the sample based on objective criteria; specifically, patients with a diagnosis of any of the 3 specific conditions that were common causes of brain death, patients aged 59 years or younger, patients who received mechanical ventilation on their first day in hospi- tal, patients who did not have a disqualifying condition (HIV, tuberculosis or cancer) and patients who survived for no longer than 1 week in hospital.

Table 1: Characteristics of patients included in the study

\begin{tabular}{|c|c|c|}
\hline Characteristic & $\begin{array}{c}\text { Transplant hospitals, } \\
\text { no. }(\%) \\
n=22515\end{array}$ & $\begin{array}{c}\text { General hospitals, } \\
\text { no. (\%) } \\
n=57231\end{array}$ \\
\hline \multicolumn{3}{|l|}{ Age, yr } \\
\hline$\leq 19$ & 1032 (4.6) & $268 \quad(0.5)$ \\
\hline $20-44$ & $2036 \quad(9.0)$ & 1920 \\
\hline $45-59$ & $3331(14.8)$ & $4742 \quad(8.3)$ \\
\hline $60-74$ & $6384(28.3)$ & $14771(25.8)$ \\
\hline$\geq 75$ & $9714(43.1)$ & $35514(62.0)$ \\
\hline Missing & $18(0.1)$ & $16(0.0)$ \\
\hline \multicolumn{3}{|l|}{ Sex } \\
\hline Male & $12014(53.4)$ & $28416(49.6)$ \\
\hline Missing & $18(0.1)$ & $16(0.0)$ \\
\hline \multicolumn{3}{|l|}{ Residence } \\
\hline Urban (v. rural) & $19778(87.8)$ & 52579 (91.9) \\
\hline Missing & $26(0.1)$ & $75 \quad(0.1)$ \\
\hline \multicolumn{3}{|l|}{ Income quintile } \\
\hline 5 (highest) & $4076(18.1)$ & $9503(16.6)$ \\
\hline 4 & $3841(17.1)$ & 9648 (16.9) \\
\hline 3 & $4067(18.1)$ & $11292(19.7)$ \\
\hline 2 & $4815(21.4)$ & $12924(22.6)$ \\
\hline 1 (lowest) & $5580(24.8)$ & $13646(23.8)$ \\
\hline Missing & $136(0.6)$ & $218 \quad(0.4)$ \\
\hline \multicolumn{3}{|l|}{ Previous care* } \\
\hline $\begin{array}{l}\geq 7 \text { visits to an outpatient } \\
\text { clinic }\end{array}$ & $17428(77.4)$ & $47496(83.0)$ \\
\hline$\geq 1$ admission to hospital & 8849 (39.3) & $23426(40.9)$ \\
\hline \multicolumn{3}{|l|}{ Arrival at hospital } \\
\hline By ambulance & $14961(66.4)$ & $42597(74.4)$ \\
\hline Direct (no ambulance) & 5037 (22.4) & $11652(20.4)$ \\
\hline Hospital-to-hospital transfer & $2517(11.2)$ & $2982 \quad(5.2)$ \\
\hline \multicolumn{3}{|l|}{ Season of admission } \\
\hline Winter & $5678(25.2)$ & $15356(26.8)$ \\
\hline Spring & $5704(25.3)$ & $14646(25.6)$ \\
\hline Summer & $5433(24.1)$ & $13264(23.2)$ \\
\hline Autumn & $5700(25.3)$ & $13965(24.4)$ \\
\hline \multicolumn{3}{|l|}{ Day of admisson } \\
\hline Weekday & $16091(71.5)$ & 41166 (71.9) \\
\hline Weekend & $6424(28.5)$ & $16065(28.1)$ \\
\hline \multicolumn{3}{|l|}{ Diagnosis } \\
\hline Traumatic brain injury & $2794(12.4)$ & $3892 \quad(6.8)$ \\
\hline Subarachnoid hemorrhage & 1200 & $1458 \quad(2.5)$ \\
\hline Intracerebral hemorrhage & 3999 (17.8) & $10777(18.8)$ \\
\hline Other neurologic death & $9431(41.2)$ & 27725 (48.4) \\
\hline Combination of above & $5091(23.6)$ & $13379(23.4)$ \\
\hline
\end{tabular}




\section{Control procedure}

We examined cornea donation as another type of donation that follows a different procurement procedure. In contrast to organ donation, cornea donation (code E108) is subject to much less time pressure and can be scheduled hours after death. The person initiating the request for cornea donation tends to be affiliated with a central agency in Ontario and is not directly attached to the particular hospital involved. Finally, the request for cornea donation usually occurs when a donor is no longer receiving life-sustaining therapies and all physiology has ended.

\section{Statistical analysis}

Our primary analysis evaluated rates of actual organ donation among patients who were potential donors and compared transplant hospitals to general hospitals. We used hierarchical logistic regression to account for patient clustering in hospitals of different sizes. Our secondary multivariable analyses accounted for demographic factors including patient age, sex, residence, socioeconomic status and time of death (year, season, day). We performed additional stratified analyses to repeat the primary comparison using only data from the subgroup

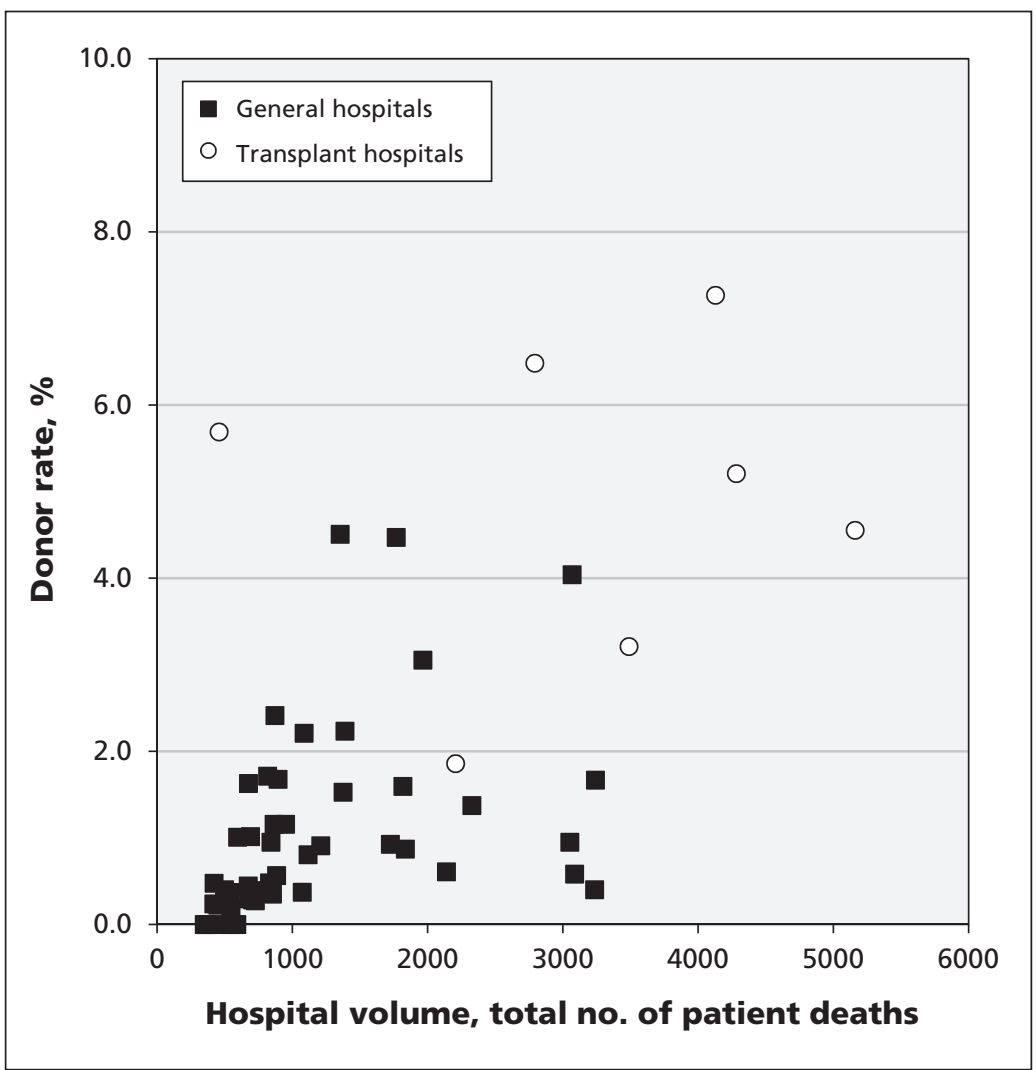

Figure 2: Rates of organ donation, by hospital, among patients who died from catastrophic neurologic conditions and the overall rate of deceased organ donation, showing a modest correlation of total deaths with overall donation rates $(r=0.61, p<0.001)$. of patients who would be most eligible for donation. We conducted all analyses using the privacy safeguards of the Institute for Clinical Evaluative Sciences.

\section{Results}

We identified a total of 87129 patients who died during the study period, of whom 1930 were identified as actual organ donors, (i.e., about 9 donors per million population annually). The number of actual donors increased with time so that the number of donors in the final year of the study was about twice that of the first year (Figure 1). The median and upper quartile of age of actual organ donors also increased with time, with an increase in median age of about 11 years (40 v. $51 \mathrm{yr}$ ) and an increase in upper quartile age of about 10 years $(51$ v. $61 \mathrm{yr})$. The 87129 deaths were distributed across 140 hospitals, of which a total of 84 hospitals averaged fewer than 20 deaths annually. After excluding these small general hospitals, we obtained a sample of 56 hospitals (40\%), 79746 deaths (92\%) and 1898 (98\%) actual organ donors.

A total of 22515 patients died at transplant hospitals and the remaining 57231 died at large general hospitals. Those who died in transplant hospitals had a distribution of demographic characteristics similar to that of patients who died at large general hospitals (Table 1). Patients who died generally lived in an urban area, had diverse characteristics and had a diagnosis of intracerebral hemorrhage or some other catastrophic neurologic condition. The main differences between the 2 settings were that patients who died in large general hospitals tended to be older and more likely to have a diagnosis of a miscellaneous catastrophic neurologic condition than those who died at a transplant hospital. Socioeconomic status was well balanced, albeit with a lower representation of people with high socioeconomic status in both groups.

Overall, 1898 of the 79746 patients included in our primary analysis became donors, for a procurement rate of about 1 in 40. Transplant hospitals accounted for 1118 donors and 22515 deaths, for a procurement rate of 5.0 per 100 deaths. Large general hospitals accounted for 780 donors and 57231 deaths, for a procurement rate of 1.4 per 100 deaths (Figures 2 and 3). This difference between hospitals was equal to a relative reduction in donation rates of about $74 \%$ (odds ratio [OR] 0.26, 95\% confidence interval [CI] 0.24-0.29), was evident in both the first and second halves of the dataset (before and after Jan. 1, 2003) and amounted to an absolute reduc- 
tion of about 121 actual organ donors each year in large general hospitals. Comparisons based on data from all hospitals (including small general hospitals) showed a relative reduction of $76 \%$ (OR 0.24, 95\% CI 0.22-0.27). Restricting analyses to the 13 largest hospitals (> 2000 total deaths) showed a relative reduction of $73 \%$ (OR $0.27,95 \%$ CI $0.24-0.31$ ).

We identified patients who would be the most eligible donors by determining those with a diagnosis of traumatic brain injury, subarachnoid hemorrhage or intracerebral hemorrhage and who were younger than 59 years, were free of disqualifying clinical conditions, received mechanical ventilation starting on their first day in hospital and survived in hospital no longer than 1 week. A total of 3961 patients met these criteria, of whom 1035 were actual donors, for an overall procurement rate of about 1 in 4 . Transplant hospitals accounted for 652 donors and 2205 deaths (procurement rate 29.6/100 deaths), large general hospitals accounted for 383 donors and 1756 deaths (procurement rate of $21.8 / 100$ deaths), for a relative reduction in donation rates of about $34 \%$ (OR $0.66,95 \% \mathrm{CI}$ 0.57-0.77).

Basic patient characteristics were additional predictors of actual organ donation. Patients aged 59 years or younger were about 10 times more likely to be actual donors than patients aged 60 years or older (Table 2). Patients with lower socioeconomic status were about $30 \%$ less likely to be actual donors than patients with higher socioeconomic status. Cause of death was a good predictor of organ donation, with the highest rates of donation among patients who died after subarachnoid hemorrhage. Accounting for all predictors yielded a relative reduction in donation rates of about $42 \%$ (OR $0.58,95 \% \mathrm{CI}$ 0.36-0.92) at large general hospitals compared with transplant hospitals.

Our control analysis showed no large differences in cornea donation when comparing different hospitals. Overall, 2104 of the 79746 patients who died became cornea donors. Transplant hospitals accounted for 688 cornea donors (procurement rate 3.1/100 deaths); large general hospitals accounted for 1416 cornea donors (procurement rate 2.5/100 deaths). This difference was equal to a relative reduction in donation rates of about $20 \%$ (95\% CI 12\%-27\%). The subgroup analyses restricted to the 3961 patients who were the most eligible donors showed a procurement rate of about 1 in 8 and a 14\% relative (but nonsignifi-

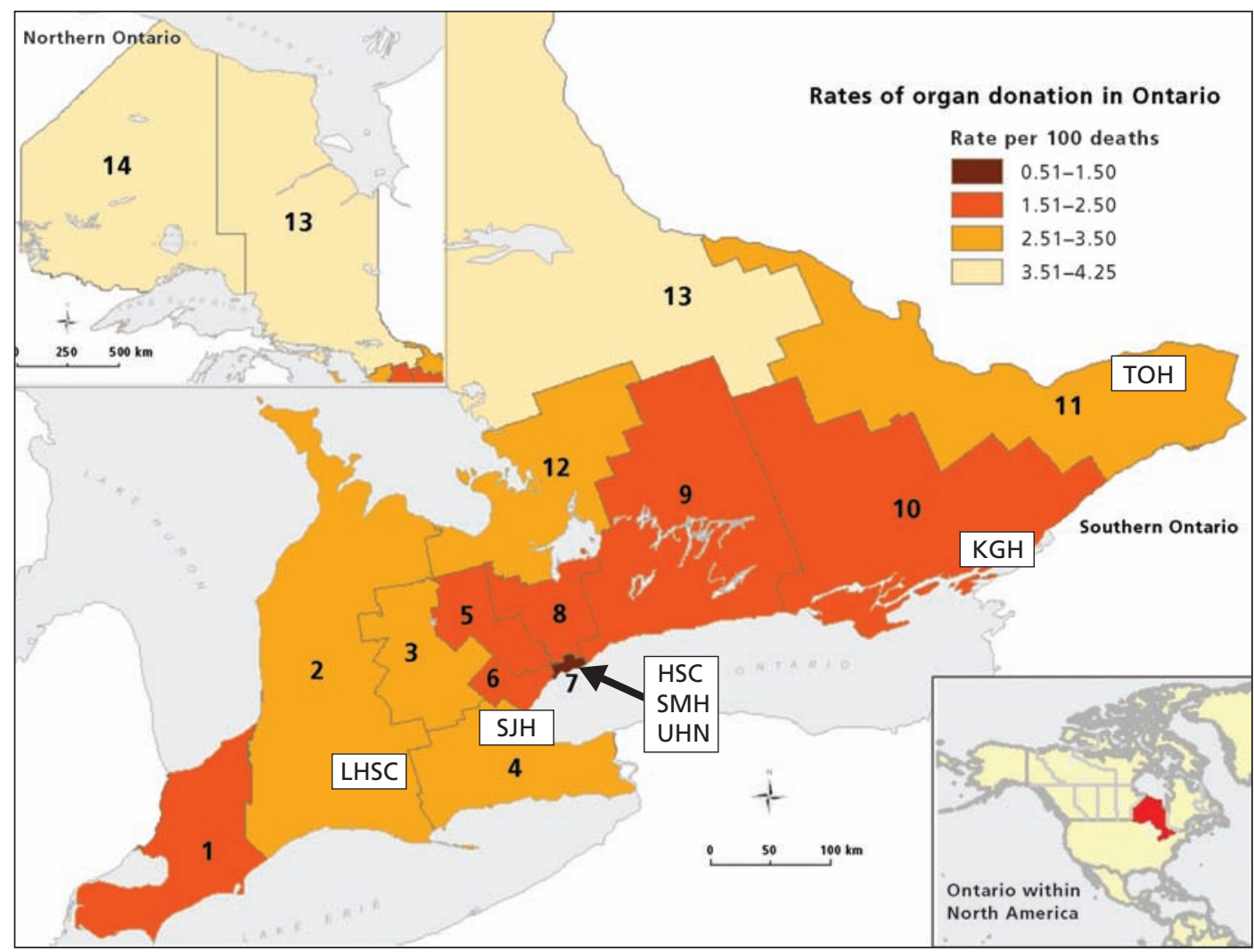

Figure 3: Organ donation by geographic area in Ontario. The 14 areas represent official Local Health Integration Networks. Note: HSC = Hospital for Sick Children, Toronto; KGH = Kingston General Hospital, Kingston; LHSC = London Health Sciences Centre, London; TOH = The Ottawa Hospital, Ottawa; SJH = St. Joseph's Healthcare, Hamilton; SMH = St. Michael's Hospital, Toronto; UHN = University Health Network, Toronto. 
Table 2: Predictors of organ procurement in 56 hospitals in Ontario

\begin{tabular}{|c|c|c|}
\hline \multirow[b]{2}{*}{ Predictor } & \multicolumn{2}{|c|}{ OR $(95 \% \mathrm{Cl})$} \\
\hline & Univariate analysis & Multivariate analysis \\
\hline \multicolumn{3}{|l|}{ Age, yr } \\
\hline$\leq 44$ & 1.00 (ref) & 1.00 (ref) \\
\hline $45-59$ & $0.50(0.44-0.56)$ & $0.50(0.44-0.56)$ \\
\hline $60-74$ & $0.11(0.09-0.12)$ & $0.13(0.11-0.15)$ \\
\hline$\geq 75$ & $0.01(0.01-0.01)$ & $0.01(0.01-0.02)$ \\
\hline \multicolumn{3}{|l|}{ Sex } \\
\hline Male & 1.00 (ref) & 1.00 (ref) \\
\hline Female & $0.99(0.90-1.09)$ & $1.39(1.25-1.54)$ \\
\hline \multicolumn{3}{|l|}{ Residence } \\
\hline Urban & 1.00 (ref) & 1.00 (ref) \\
\hline Rural & $1.78(1.55-2.05)$ & $1.11(0.96-1.30)$ \\
\hline \multicolumn{3}{|l|}{ Income quintile } \\
\hline 5 (highest) & 1.00 (ref) & 1.00 (ref) \\
\hline 4 & $1.11(0.96-1.28)$ & $0.89(0.76-1.04)$ \\
\hline 3 & $0.97(0.84-1.13)$ & $0.81(0.69-0.95)$ \\
\hline 2 & $0.77(0.66-0.89)$ & $0.63(0.54-0.74)$ \\
\hline 1 (lowest) & $0.78(0.68-0.91)$ & $0.63(0.53-0.73)$ \\
\hline \multicolumn{3}{|l|}{ Prior care } \\
\hline Visits to outpatient clinics* & $0.25(0.22-0.27)$ & $0.66(0.59-0.74)$ \\
\hline Admissions to hospital* & $0.36(0.32-0.41)$ & $0.66(0.57-0.76)$ \\
\hline \multicolumn{3}{|l|}{ Arrival } \\
\hline By ambulance & 1.00 (ref) & 1.00 (ref) \\
\hline Direct (no ambulance) & $0.60(0.53-0.69)$ & $0.81(0.70-0.93)$ \\
\hline Hospital-to-hospital transfer & $0.81(0.68-0.96)$ & $1.06(0.86-1.30)$ \\
\hline \multicolumn{3}{|l|}{ Season } \\
\hline Winter & 1.00 (ref) & 1.00 (ref) \\
\hline Spring & $0.92(0.81-1.05)$ & $0.91(0.79-1.05)$ \\
\hline Summer & $1.05(0.92-1.20)$ & $0.94(0.81-1.08)$ \\
\hline Autumn & $1.10(0.96-1.25)$ & $1.06(0.92-1.21)$ \\
\hline \multicolumn{3}{|l|}{ Day } \\
\hline Weekday & 1.00 (ref) & 1.00 (ref) \\
\hline Weekend & $0.97(0.87-1.07)$ & $0.94(0.84-1.05)$ \\
\hline \multicolumn{3}{|l|}{ Diagnosis } \\
\hline Traumatic brain injury & 1.00 (ref) & 1.00 (ref) \\
\hline Subarachnoid hemorrhage & $1.99(1.70-2.34)$ & $1.55(1.29-1.86)$ \\
\hline Intracerebral hemorrhage & $0.51(0.44-0.59)$ & $0.90(0.76-1.06)$ \\
\hline Other neurologic death & $0.21(0.18-0.25)$ & $0.31(0.27-0.37)$ \\
\hline Combination of above & $0.53(0.46-0.61)$ & $0.72(0.61-0.84)$ \\
\hline \multicolumn{3}{|l|}{ Exclusions } \\
\hline Disqualifying condition $t$ & $0.06(0.03-0.11)$ & $0.06(0.03-0.12)$ \\
\hline \multicolumn{3}{|l|}{ Hospital } \\
\hline Transplant & 1.00 (ref) & 1.00 (ref) \\
\hline Large general & $0.17(0.09-0.34)$ & $0.58(0.36-0.92)$ \\
\hline
\end{tabular}

cant) increase in cornea donation (OR 1.14, 95\% CI 0.94-1.37) at large general hospitals compared with transplant hospitals.

\section{Interpretation}

In this population-based cohort study, rates of organ donation in Ontario were low, showed increases over time and were highest among patients less than 45 years of age with higher socioeconomic status. An additional predictor of organ donation was not a characteristic of the patient, but of the hospital; namely, whether the hospital itself had clinical services for transplant recipients. The apparent decrease in donations in otherwise large general hospitals was difficult to attribute to chance, persistent over time and not fully explained by patient characteristics. Together, these data underscore the effect of circumstances, rather than personal preferences, on profound medical decisions. ${ }^{24}$

Actual organ donation is linked to several personal factors including the patient's ethnicity and religious beliefs..$^{25,26}$ Interactions between clinicians and substitute decision-makers can also influence consent rates for organ donation. ${ }^{9-11}$ Hospital factors associated with actual donation include large size, the availability of neurosurgical services, the presence of an emergency department and various unmeasured attributes. ${ }^{2,27}$ The main limitations of previous studies were small sample, the use of self-report surveys or limited time spans. One previous study suggested that hospital identity might influence organ donation rates based on chart review at a subset of volunteer hospitals and was restricted to patients who were formally documented as having brain death. ${ }^{2}$

\section{Limitations}

Hospital identity is a reflection of multiple attributes, including the availability of specialty services such as neurosurgery, neurology and trauma. Large general hospitals, therefore, might differ so that some could have higher than average procurement rates and, in theory, rival transplant hospitals. A more detailed analysis of all potential hospital attributes exceeds the limits of available data and would not nullify our main finding — the many missed opportunities for organ donation at large general hospitals. More generally, opportunities for improvement may vary depending on exact hospital identity, thus suggesting that procurement policies need to be tailored to local circumstances.

Our study is not a randomized trial that minimizes confounding. The incidence of brain death, prehospital transportation of patients who are dying and staffing of hospitals are important determinants of donation rates that cannot be 
assigned in a controlled experiment. One explanation for our results could be that some hospitals that are inherently enthusiastic about organ donation are early adopters of clinical services for transplant recipients. Alternatively, communities with positive attitudes toward donation might be the most successful at obtaining clinical transplant services at their own hospitals. Regardless of the explanation, our research suggests that actual organ donation may not be an accurate reflection of individual patient wishes.

We used codes for organ donation that were specific rather than sensitive, and they may have missed unidentified cases of organ donation; however, fallible coding is unlikely to explain the size of the discrepancy we saw between transplant hospitals and large general hospitals. In addition, we evaluated a region distinguished by universal health care and public awareness campaigns about transplantation; hence, shortfalls in donation for other regions may be larger. Finally, the ideal rate of organ donation is not known given the importance of patient preferences and community circumstances.

\section{Conclusion}

Our research suggests a lower frequency of deceased organ donation at large general hospitals than at transplant hospitals. In particular, we found a substantial age gradient underlying the shortfall in organ donation. This gradient may be partly explained by appropriate medical judgment, given that older organs are sometimes unsuitable for transplantation to young recipients. ${ }^{28-31}$ However, unfair age discrimination may be an additional explanation. ${ }^{32,33}$ Indeed, there is no age limit for organ donation, and successful organ procurement can occur from patients older than 80 years of age. ${ }^{34,35}$

The practice patterns in large hospitals are a reflection of identity, education, incentives and myriad other factors. Thus, addressing the shortfall in organ donation rates could include training, encouragement, regulations, policies, consent procedures and academic detailing campaigns targeting large general hospitals. Any of these approaches would require tact, is prone to misinterpretation and is rarely included in national campaigns for organ donation. The current data suggest, however, that prevailing practices lead to missed potential opportunities for solid organ donation in large general hospitals.

\section{References}

1. Gortmaker SL, Beasley CL, Brigham LE, et al. Organ donor potential and performance: size and nature of the organ donor shortfall. Crit Care Med 1996;24:432-9.

2. Sheehy E, Conrad SL, Brigham LE, et al. Estimating the number of potential organ donors in the United States. $N$ Engl J Med 2003;349:667-74.
3. Scales DC, Granton JT. Care of the critically ill transplant patient. In: Principles of citical care. Hall JB, Schmidt GA, Wood LDH, editors. 3rd ed. New York (NY): McGraw-Hill; 2005.

4. Hauptman PJ, O'Connor KJ. Procurement and allocation of solid organs for transplantation. N Engl J Med 1997;336:422-31.

5. Shemie SD, Ross H, Pagliarello J, et al. Organ donor management in Canada: recommendations of the Forum on Medical Management to Optimize Donor Organ Potential. CMAJ 2006; 174:S13-32.

6. Wood KE, Becker BN, McCartney JG, et al. Care of the potential organ donor. $N$ Engl J Med 2004;351:2730-9.

7. Bell CM, Redelmeier DA. Mortality among patients admitted to hospitals on weekends as compared with weekdays. $N$ Engl J Med 2001;345:663-8.

8. Greer DM, Varelas PN, Haque S, et al. Variability of brain death determination guidelines in leading US neurologic institutions. Neurology 2008;70:284-9.

9. Siminoff LA, Gordon N, Hewlett J, et al. Factors influencing families' consent for donation of solid organs for transplantation. JAMA 2001;286:71-7.

10. Ghorbani F, Khoddami-Vishteh HR, Ghobadi O, et al. Causes of family refusal for organ donation. Transplant Proc 2011;43:405-6.

11. Simpkin AL, Robertson LC, Barber VS, et al. Modifiable factors influencing relatives' decision to offer organ donation: systematic review. BMJ 2009;338:b991.

12. Kahneman D. Thinking, fast and slow. New York (NY): Farrar, Straus and Giroux; 2011.

13. Ross L, Nisbett RE. The person and the situation: perspectives of social psychology. New York (NY): McGraw-Hill; 1991.

14. LeBoeuf RA, Shafir E, Bayuk JB. The conflicting choices of alternating selves. Organ Behav Hum Decis Process 2010;111:48-61.

15. Rachlin H, Locey M. A behavioral analysis of altruism. Behav Processes 2011;87:25-33.

16. Cloutier R, Baran D, Morin JE, et al. Brain death diagnoses and evaluation of the number of potential organ donors in Quebec hospitals. Can J Anaesth 2006;53:716-21.

17. Kompanje EJ, Bakker J, Slieker FJ, et al. Organ donations and unused potential donations in traumatic brain injury, subarachnoid haemorrhage and intracerebral haemorrhage. Intensive Care Med 2006;32:217-22.

18. Opdam HI, Silvester W. Identifying the potential organ donor: an audit of hospital deaths. Intensive Care Med 2004;30:1390-7.

19. Williams JL, Young W. Inventory of studies on the accuracy of Canadian health administrative databases. Ottawa $(\mathrm{ON})$ : Institute for Clinical Evaluative Sciences; 1996.

20. Wilkins R, Peters PA. Automated geographic coding based on the Statistics Canada Postal Code Conversion Files. Ottawa (ON): Health Statistics Division, Statistics Canada; 2004.

21. Iron K, Goel V, Williams JI. Concordance with hospital discharge abstracts and physician claims for surgical procedures in Ontario. North York (ON): Institute for Clinical Evaluative Sciences; 1995.

22. CIHI data quality study of emergency department visits for 2004-2005. Vol. 2: Main study findings. Ottawa (ON): Canadian Institute for Health Information; 2008.

23. Schull MJ, Hatcher CM, Guttmann A, et al. Development of a consensus on evidence-based quality of care indicators for Canadian emergency departments. North York (ON): Institute for Clinical Evaluative Sciences; 2010.

24. Ross L, Nisbett RE. The person and the situation: perspectives of social psychology. New York (NY): McGraw-Hill; 1991.

25. Barber K, Falvey S, Hamilton C, et al. Potential for organ donation in the United Kingdom: audit of intensive care records. $B M J$ 2006;332:1124-7.

26. Kennedy I, Sells RA, Daar AS, et al. The case for "presumed consent" in organ donation. International Forum for Transplant Ethics. Lancet 1998;351:1650-2.

27. Horvat LD, Cuerden MS, Kim J, et al. Informing the debate: rates of kidney transplanation in nations with presumed consent. Ann Intern Med 2010;153:641-9.

28. Chavalitdhamrong D, Gill J, Takemoto S, et al. Patient and graft outcomes from deceased kidney donors age 70 years and older: an analysis of the Organ Procurement Transplant Network/ United Network of Organ Sharing database. Transplantation 2008;85:1573-9.

29. Remuzzi G, Cravedi P, Perna A, et al. Long-term outcome of renal transplantation from older donors. N Engl J Med 2006;354:343-52.

30. Moreso F, Seron D, Gil-Vernet S, et al. Donor age and delayed graft function as predictors of renal allograft survival in rejection-free patients. Nephrol Dial Transplant 1999;14:930-5.

31. Lai Q, Melandro F, Levi Sandri GB, et al. Use of elderly donors for liver transplantation: Has the limit been reached? J Gastrointestin Liver Dis 2011;20:383-7.

32. Jassal SV, Krahn MD, Naglie G, et al. Kidney transplantation in the elderly: a decision analysis. J Am Soc Nephrol 2003;14:187-96. 
33. Young A, Kim SJ, Speechley R, et al.; Donor Nephrectomy Outcomes Research Network. Accepting kidneys from older living donors: Impact on transplant recipient outcomes. Am J Transplant 2011;11:743-50.

34. Singhal A, Sezginsoy B, Ghuloom AE, et al. Orthotopic liver transplant using allographs from the geriatric population in the United States: Is there any age limit? Exp Clin Transplant 2010;8:196-201.

35. Hubbard WJ, Dashti N. Age and transplantation - A topic for biomedicine or bioethics? Aging Dis 2011;2:181-5.

Affiliations: From the Department of Medicine (Redelmeier, Scales), University of Toronto; the Institute for Clinical Evaluative Sciences (Redelmeier, Scales); the Trillium Gift of Life Network (Markel); the Department of Critical Care Medicine (Scales), Sunnybrook Health Sciences Centre; and the Interdepartmental Division of Critical Care (Scales), University of Toronto, Toronto, Ont.

Contributors: All of the authors contributed to the conception and design of the study, the analysis and interpretation of the data, and drafting the manuscript. All of the authors approved the final version of the manuscript. Donald Redelmeier is the guarantor of the data and results.

Funding: This project was supported by the Canada Research Chair in Medical Decision Sciences, a New Investigator Award from the Canadian Institutes of Health Research, a Fellowship in Translational Health Research from the Physicians' Services Incorporated Foundation, and an unrestricted grant from the Trillium Gift of Life Network. The funding organizations had no role in the design and conduct of the study; collection, management, analysis and interpretation of the data; and preparation, review or approval of the manuscript.

Acknowledgements: The authors thank Sonny Dhanani, Barry McLellan, Sam Shemie, Amit Garg and Robbie Redelmeier for helpful comments. The views expressed in this paper do not necessarily reflect those of the Ontario Ministry of Health and Long-term Care. 